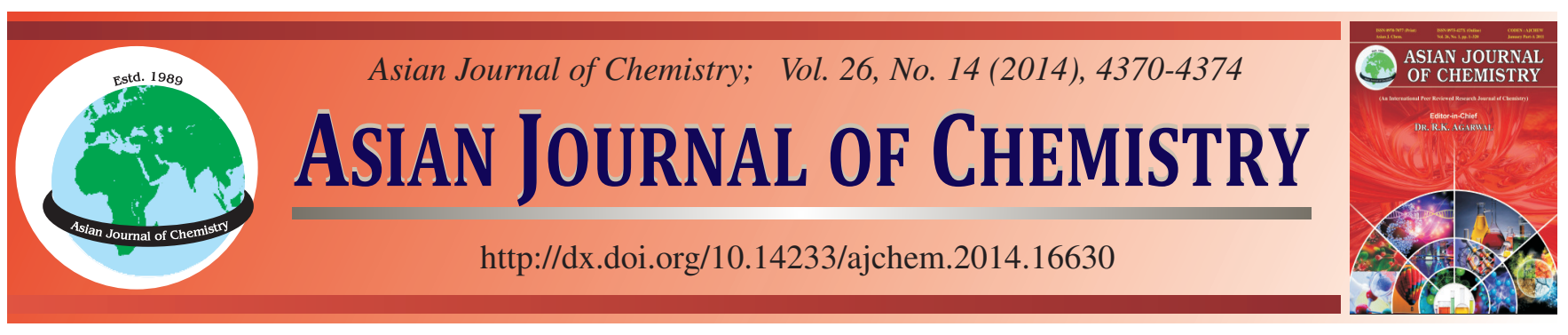

\title{
Preparation and Characterization of Ascorbic Acid Microcapsules Based on Gelatin Extracted from Tilapia Scale
}

\author{
Peng Li ${ }^{1,2}$ and XuAN Ri SHEN ${ }^{1,2, *}$
}

${ }^{1}$ College of Food Science and Technology, Hainan University, Hainan, P.R. China

${ }^{2}$ Key Laboratory of Tropical Biological Resources of Ministry of Education, Hainan, P.R. China

*Corresponding author: Fax: +86 898 66261813; Tel: +86 13518898909; E-mail: shenxuanri2009@163.com

Gelatin extracted from tilapia scale (FSG) is used to encapsulate ascorbic acid under ultrasonic to demonstrate that FSG is a promising wall material in microencapsulation. The microcapsules are prepared with $15 \mathrm{mg} / \mathrm{mL}$ of gelatin and factors including concentration of transglutaminase and ascorbic acid, amount of emulsifier and temperature of solidification that related to the encapsulation rate are studied. Finally, the microcapsule with the highest encapsulation rate of $81.17 \%$ is spheroid with average particle size of $5.73 \mu \mathrm{m}$. The ascorbic acid retention in the microcapsule is $53.39 \%$ at $5{ }^{\circ} \mathrm{C}$ and $5.79 \%$ at $25{ }^{\circ} \mathrm{C}$ after 30 days of storage. While at $37{ }^{\circ} \mathrm{C}$, it is only 10 $\mathrm{h}$, the encapsulation rate of ascorbic acid reaches $41.08 \%$. Thus, controlled-release without phase separation is followed with time elapsed and could be adjusted by storage temperature. Gelatin extracted from tilapia scale is an applicable wall material in microencapsulation and the microcapsule has real potential to be used in pharmaceuticals and cosmetic industry.

Keywords: Controlled-release, Gelatin, Tilapia, Scale, Microencapsulation, Transglutaminase, Ascorbic acid.

\section{INTRODUCTION}

Tilapia is potential to become the most important aquaculture species in the world ${ }^{1}$ that has been widely found in tropical and subtropical areas. In 2010, the world production of farmed tilapias reached 3.2 million metric tons and about $35 \%$ was produced in China. Scale as processing waste makes up approximately $1 \%$ of the total weight of the processed fish. Rational utilization of its processing waste plays an important role in environmental protection and comprehensive utilization. Fish scale is rich in collagen and can be a resource to extract the gelatin ${ }^{2}$. Nowadays, the main resource of gelatin is still the land mammal, but the development of fishes as new resources of gelatin in the last decade is attractive ${ }^{3-5}$. There are many reasons for this tendency, apart from the well-known socio-culture and sanitary aspects and spread of disease such as bovine spongiform encephalopathy in pigs and cattle ${ }^{6}$, the rising interest in putting by-products from fish industry to good use is another most important reason ${ }^{7,8}$. Even though there are many researches on properties of gelatin extracted from fish ${ }^{9-12}$, which concluded that properties of gelatin from cold water fish $^{7}$ are worse than mammalian gelatin's while properties of gelatin from warm water fish are kind of similar to mammalian gelatin' $\mathrm{s}^{13,14}$. However, there is few application of fish gelatin neither cold water's nor warm water's. It is worth well to find the application area of fish gelatin that could get its maximum benefit.

Microencapsulation is an effective way to wrap active material $^{15}$, which known as core material by microcapsules and it has potential to extend applications of these active materials ${ }^{16}$. Gelatin has been used as wall material in microencapsulation for a long time. We took a preliminary experiment and found that gelatin extracted from tilapia scale (FSG) would bring a higher encapsulation rate than mammalian gelatin (MG) in embedding ascorbic acid. Ascorbic acid has a broad spectrum of beneficial activities ${ }^{17}$ but its rapid degradation in aqueous solution is still a major drawback in practical application. Microcapsule could provide a protective wall for ascorbic acid, so that ascorbic acid could be effective in a relatively long time and be released when necessary.

Thus, the objective of this study is to develop gelatin extracted from tilapia scale as wall material to embedding ascorbic acid. In order to maximize the encapsulation rate of ascorbic acid microcapsule made with $15 \mathrm{mg} / \mathrm{mL}$ FSG, the relationship of factors including concentration of transglutaminase (TG) as cross-linking agent and ascorbic acid as core material, amount of AEO-9 as emulsifier and temperature of solidification between encapsulation rate are discussed. The particle size and stability of microcapsules are important for 
the application of microcapsule, hence, the morphology and particle size distribution of the capsules prepared with FSG were characterized. Furthermore, controlled-release of ascorbic acid from the capsules was also detected at 5,25 and $37^{\circ} \mathrm{C}$, respectively for further application of the microcapsule.

\section{EXPERIMENTAL}

The dried scale of tilapia was obtained from Hainan Golden Spring Food Co., Ltd (Haikou, China). Ascorbic acid was purchased from Guangzhou chemical regent factory (Guangzhou, China). Trangsglutaminase (TG) was obtained from Nan Ning Pangbo Biological Engineering Co., Ltd (Nanning, China). Mammalian gelatin (MG) was purchased from Tianjin Funchen Reagents Factory (Tianjin, China). Polyoxyethylene fatty alcohol (AEO-9) was purchased from Guangzhou Kanghong Chemical Co., Ltd (Guangzhou, China). Liquid paraffin was chemical grade. All other solvents used in the study were of analytical grade.

Extraction of tilapia scale gelatin: $300 \mathrm{~g}$ dried scale of tilapia was immersed in $1500 \mathrm{~mL} 30 \% \mathrm{HCl}$ solution for $15 \mathrm{~min}$ with occasionally stirring. And then the scale was immersed in $1000 \mathrm{~mL} 0.1 \mathrm{M} \mathrm{NaOH}$ for $12 \mathrm{~h}$ under magnetic stirring. The steps above were to remove impurities including ash, fat and other protein. And after each immersing, the fish scale would be washed with tap water until the $\mathrm{pH}$ of the washing fluid to be 7 . Next, drying the surface of fish scale before it was mixed with $1600 \mathrm{~mL}$ distilled water at temperature $95{ }^{\circ} \mathrm{C}$ for $3 \mathrm{~h}$. The extracted solution was collected by vacuum pump and filler and then being freeze dried for later experiment.

Preparation of microcapsules: The initial condition for preparing microcapsules was described below. $1 \mathrm{~mL}$ of solution containing gelatin $(15 \mathrm{mg} / \mathrm{mL})$ and ascorbic acid $(7.5$ $\mathrm{mg} / \mathrm{mL}$ ) was injected into the solution formed with liquid paraffin $(20 \mathrm{~mL})$ and AEO-9 $(100 \mu \mathrm{L})$. Ultrasound could help to obtain a narrower size distribution and higher microencapsulation yield ${ }^{18}$, so the study take ultrasonic cleaner (XO520DTD) to vibrate the mixture for $10 \mathrm{~min}$, while the temperature was controlled under $25 \pm 1^{\circ} \mathrm{C}$. Then, the $\mathrm{pH}$ of the mixture was adjusted to about 6.0 by $10 \% \mathrm{NaOH}$ before adding $1 \mathrm{~mL}$ of TG $(0.1 \mathrm{~g} / \mathrm{mL})$ by injection taking the most appropriate $\mathrm{pH}$ of TG into consideration ${ }^{19}$. Next, $30 \mathrm{~mL} 50 \%$ ethanol was added to the mixture by injection too. Each injection took $10 \mathrm{~s}$ with 1 min of magnetic stirring. After these steps, the solution was put into a temperature-controlled water bath for $3 \mathrm{~h}$ at $40{ }^{\circ} \mathrm{C}$ (temperature of solidification). This step was needed by both the TG to cross-link gelatin and the liquid paraffin to stratify completely. Subsequently, the top layer containing liquid paraffin was removed and $10 \% \mathrm{NaOH}$ was added to the rest of solution until the $\mathrm{pH}$ came to 10 which was hold within $10 \mathrm{~min}$ to inactivate the TG. After that, the $\mathrm{pH}$ of the liquid was adjusted to about 7 with $10 \%$ acetic acid for the storage and usage. So much for that, the microcapsules has been prepared.

For a better encapsulation rate, the factors of the concentration of TG $(0,0.05,0.1,0.15$ and $0.2 \mathrm{~g} / \mathrm{mL})$, the volume of the emulsifier $(0,50,100,150,200 \mu \mathrm{L})$, the concentration of ascorbic acid $(3.75,7.5,11.25,15 \mathrm{mg} / \mathrm{mL})$ and temperature of solidification $\left(20,40\right.$ and $\left.60{ }^{\circ} \mathrm{C}\right)$ were discussed on the base of the initial condition. And each factor is investigated according to the results of the previous factors and providing a foundation for the next one. The condition that could obtain the highest encapsulation would be optimized by orthogonal test $\left[\mathrm{L}_{9}\left(3^{4}\right)\right]$ for further research.

Encapsulation rate: The encapsulation rate was determined as a function of the difference between the total mass of ascorbic acid added to the preparing solution and that being detected ascorbic acid outside microcapsules. $1 \mathrm{~mL}$ microcapsule solution was dialyzed against $20 \mathrm{~mL}$ distilled water with dialysis membrane (MWCO 8000-14000, flat width: 34 $\mathrm{mm}$, Solarbio) for $24 \mathrm{~h}$ at $5{ }^{\circ} \mathrm{C}$ in a light-resistant container. Then the content of ascorbic acid in the $20 \mathrm{~mL}$ water was determined by phosphomolybdic acid colorimetry ${ }^{20}$. The standard curve of ascorbic acid is A760 nm $=0.0025 \mathrm{x}+$ $0.0005, \mathrm{R} 2=0.9990)$. Where $\mathrm{x}$ is the mass of ascorbic acid $(\mu \mathrm{g})$ in the sample and A760 $\mathrm{nm}$ was the absorbance of sample at $760 \mathrm{~nm}$. Therefore, the encapsulation rate of the microcapsules could be calculated using the equation below. $\mathrm{W}=$ $\left(1-20 \mathrm{M} / \mathrm{M}_{0}\right) \times 100 \%$, where $\mathrm{W}$ was the encapsulation rate $(\%), \mathrm{M}_{0}$ was the total mass of ascorbic acid $(\mu \mathrm{g})$ added in $1 \mathrm{~mL}$ of the microcapsule solution and $20 \mathrm{M}$ was the mass of ascorbic acid in the $20 \mathrm{~mL}$ distilled water.

Morphological characteristics of microcapsules: Optical microscopy was recorded by an Olympus BX41TF microscope. For the further investigation, the solution of microcapsule was concentrated by vacuum concentrator at $45^{\circ} \mathrm{C}$ until the volume into a third. Then it was dried by spray dryer (YC-015, China) with inlet air temperature of $230^{\circ} \mathrm{C}$ and outlet air temperature of $93.9{ }^{\circ} \mathrm{C}$. The obtained microcapsule's powder was white. After metal spraying process, the dried microcapsules were characterized by scanning electronic (SEM) microscopy (S-3000N, Hitachi, Japan).

Particle size analysis: The laser diffraction particle analyzer (Winner 2000, China) was used to determine the particle size and size distribution without sedimentation medium. And 10s of ultrasonic treatment for the microcapsules has hardly any influence on the analysis results.

Controlled-release characteristics of microcapsules: The solution of microcapsules was stored in a light-resistant container. For the microcapsules under storage temperature of 5 and $25{ }^{\circ} \mathrm{C}$, the encapsulation rate was determined every day in 30 days respectively. Both of ascorbic acid and FSG are potential to be applied in human being's cosmetic and pharmaceutical, hence, the human being's body temperature was taking into consideration on the controlled release properties. Encapsulation rates of samples stored at $37^{\circ} \mathrm{C}$ were determined every hour in $10 \mathrm{~h}$ too.

\section{RESULTS AND DISCUSSION}

Analysis of encapsulation rate: Trangsglutaminase cross-links protein chains through the formation of the covalent linkages between $\gamma$-carboxyamide groups of peptide-bound glutamine residues and $\varepsilon$-amino groups of lysine ${ }^{21}$. Trangsglutaminase was added after the initially forming of microcapsules, so it was conjectured that the trangsglutaminase acted like a lock to prevent the release of ascorbic acid from the 
initially formed microcapsules. In order to evaluate whether the cross-linking action of TG would affect the encapsulation rate, we performed the experiment with different concentrations of TG. The relationship between TG and encapsulation rate showed in Fig. 1a. It indicated that the cross-linking would affect the encapsulation rate. And for the concentration of TG, from 0 to $0.1 \mathrm{~g} / \mathrm{mL}$, the encapsulation rate increased with the increasing of the TG concentration, but when the TG concentration exceeded $0.1 \mathrm{~g} / \mathrm{mL}$, the encapsulation rate maintained around $74.32 \%$. This phenomenon supported the deduction above. Thus, the concentration of TG would not improve the encapsulation rate, but help to prevent the ascorbic acid leaking from the formed wall of gelatin. When the concentration of TG came to $0.1 \mathrm{~g} / \mathrm{mL}$, it was close to the critical value that gelatin need for the formed wall of microcapsules being crosslinked. Thus, $01 \mathrm{~g} / \mathrm{mL}$ TG was the suitable concentration in this test. AEO-9 is nonionic surfactants with high surface activity which is a compound of amphipathic structure and does not dissociate into ions in water. Thus, the solution of AEO-9 has low surface tension and low critical micelle concentration $^{22}$. However, too little emulsifier is not enough for the gelatin to adsorb in the solution and it will lead to an unstable system, while too much of emulsifier would bring out a stable system, at the same time, it would generate a great deal of foam. Therefore, the proper amount of emulsifier used in the process should be discussed. The results presented in figure $1 \mathrm{~b}$ and the proper amount of emulsifier was $150 \mu \mathrm{L}$ with the highest encapsulation rate of $76.60 \%$ in this part. The relationship between the ratio of FSG to ascorbic acid and encapsulation rate indicated that $15 \mathrm{mg} / \mathrm{mL}$ of FSG could get a better encapsulation rate when the concentration of ascorbic acid was $7.5 \mathrm{mg} / \mathrm{mL}$ (Fig. 1c). The concentration of FSG and ascorbic acid was lower comparing to the mass production (produced with $5 \%$ gelatin and $1.1 \%$ sodium alginate $\mathrm{w} / \mathrm{v})^{23}$, but it also need to be researched about the amount of ascorbic acid that could be embedded so that a high efficiency microcapsules could be produced. It turned out that $15 \mathrm{mg} / \mathrm{mL}$ of FSG with $7.5 \mathrm{mg} / \mathrm{mL}$ ascorbic acid could obtained the most efficiency microcapsule in this section. Solidification temperature was to provide a adapt environment for the TG to cross-link FSG. Fig. 1d presented that the solidification temperature has a big effect on the encapsulation rate too. And the encapsulation reached the better level at $40{ }^{\circ} \mathrm{C}$ which in line with the results concluded by Nielsen ${ }^{24}$. The results above was optimized by orthogonal experiment with four factors and three levels $\left[\mathrm{L}_{9}\left(3^{4}\right)\right]$. It indicated that the way to preparing the micro-capsules has advantages of simple and easily-controlled process with good repeatability. And the finally condition for the process
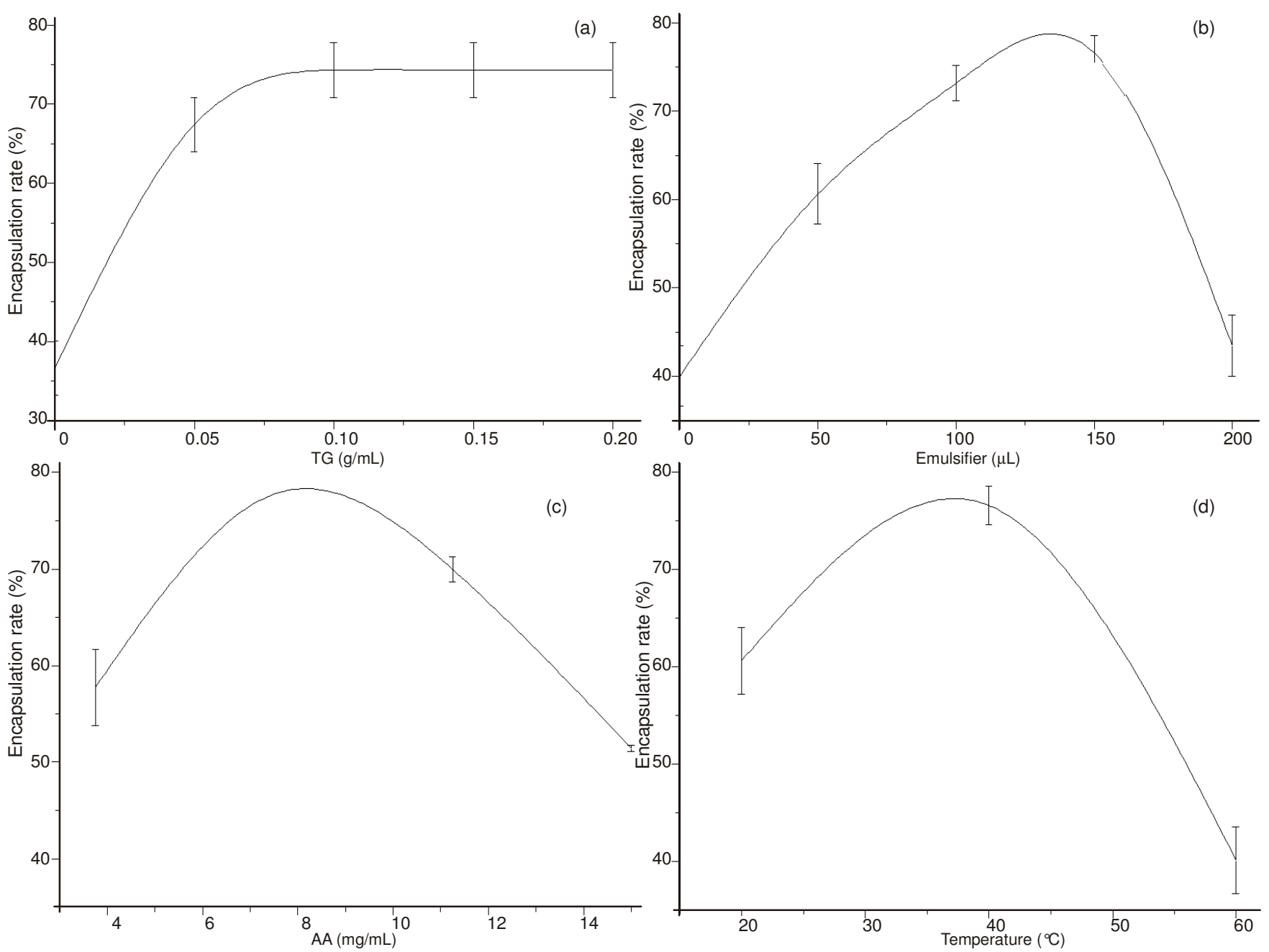

Fig. 1. Relationship between factors and encapsulation rate (a: Emulsifier, b: TG, c: AA, d: Temperature; Data are presented as mean \pm SD $(n=3)$ ) 
of preparing the microcapsule with an encapsulation of $81.17 \%$ was $15 \mathrm{mg} / \mathrm{mL}$ FSG, $7.5 \mathrm{mg} / \mathrm{mL}$ ascorbic acid, $0.12 \mathrm{mg} / \mathrm{mL}$ TG, $150 \mu \mathrm{L}$ AEO- 9 and $40{ }^{\circ} \mathrm{C}$ solidification temperature.

To test whether the FSG has advantage in encapsulation rate than mammals gelatin, the mammalian gelatin was used to prepare ascorbic acid microcapsules under the optimized condition. The results indicated that mammalian gelatin only obtained microcapsules with encapsulation of $43.5 \%$ which was lower than the $81.17 \%$. Therefore, the FSG was promising in microencapsulation technology, but the essence of the difference between mammalian gelatin and FSG need further investigation.

Morphology and particle size of microcapsules: The morphologies of the obtained microcapsule made with FSG in solution were manifested in Fig. 2A. All the microcapsules observed by Olympus BX41TF were small spheres and although some microcapsule possessed a particle sizes lager than $20 \mu \mathrm{m}$, the main distribution of particle size of the obtained microcapsules was under $10 \mu \mathrm{m}$. Fig. 2B, 2C, 2D were close-up shots of different part of Fig. 2A.

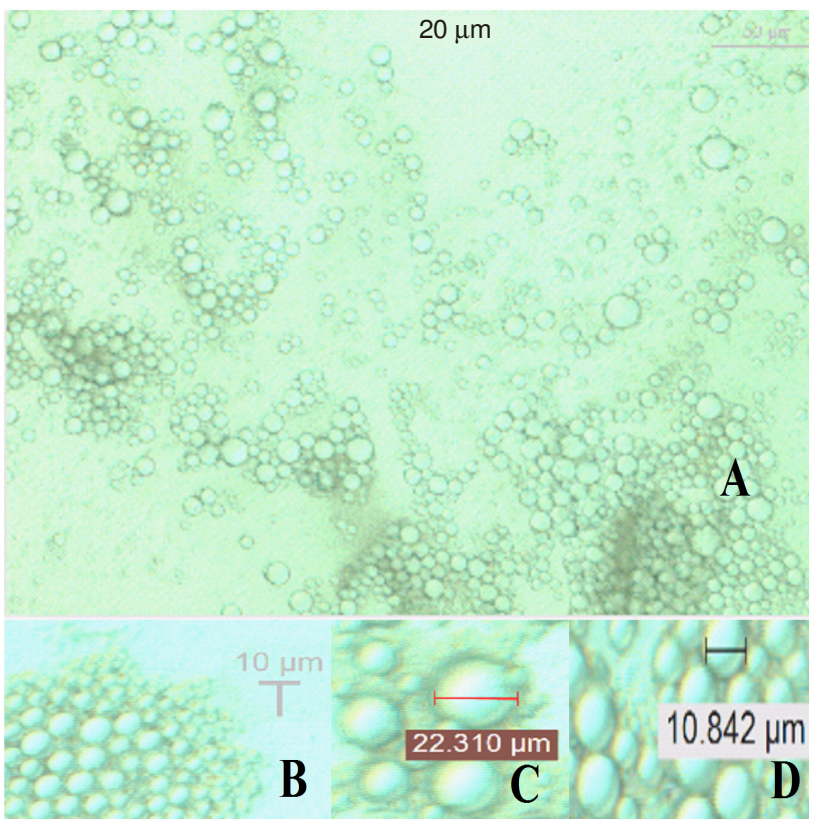

Fig. 2. Morphology of the microcapsules by microscope

The average particle size of the microcapsule was $5.73 \mu \mathrm{m}$ and $50 \%$ of the microcapsules owned the particle size were less than $4.83 \mu \mathrm{m}$ (Fig. 3). Generally speaking, the particle size distribution of the microcapsules was focused on 4 to $8 \mu \mathrm{m}$ which was adapted to many applications such as cosmetic and pharmaceutical. After $30 \mathrm{~d}$ at room temperature, the average particle size became to be $5.47 \mu \mathrm{m}$ which closed to the initial vale. It indicated that the structure of the microcapsules were stable.

Powder of the microcapsules was obtained by spry drying was observed by SEM and the result showed in Fig. 4. Almost all the surface of the microcapsules in Fig. 4 was folded which was formed during the spray-drying process because of the pressure within the microcapsules ${ }^{25}$. On the whole, the particle size range of the microcapsules was similar to the results in Fig. 3.

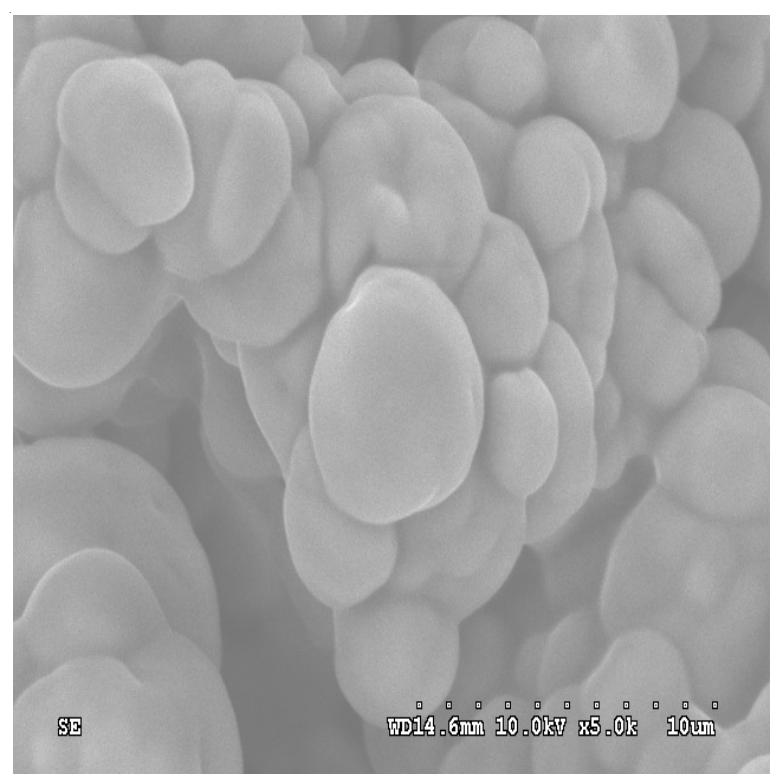

Fig. 3. Morphology of the microcapsules by SEM

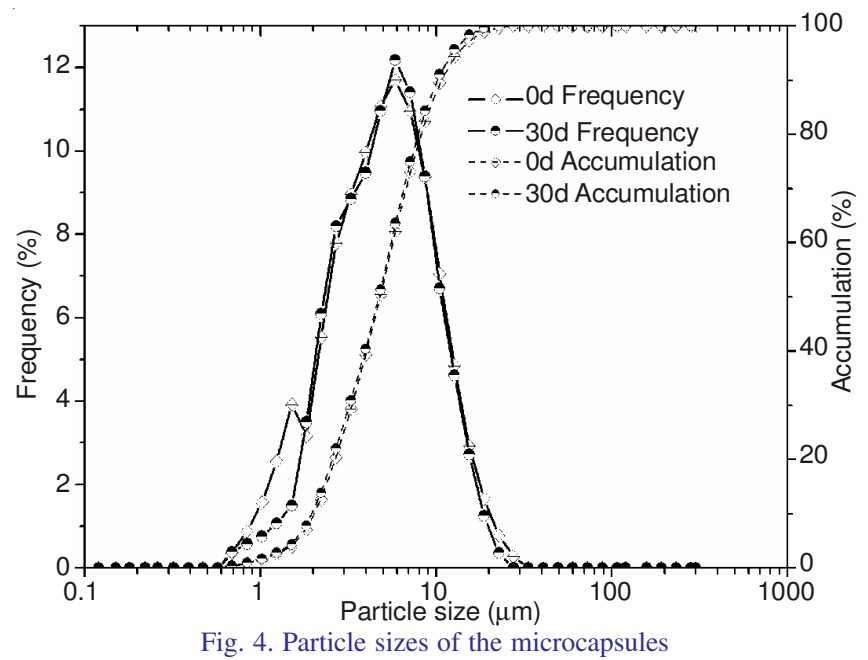

Controlled-release of ascorbic acid: The encapsulation rate of ascorbic acid was changing with time under different temperature in different rates as shown in Fig. 5. As the increasing of temperature, the releasing rate was increasing. In $30 \mathrm{~d}$, the encapsulation rate was 43.5 and $4.7 \%$ at $5{ }^{\circ} \mathrm{C}$ and $25^{\circ} \mathrm{C}$, respectively. $37{ }^{\circ} \mathrm{C}$ was close to the temperature of human beings, so the controlled-release quality of microcapsule at $37^{\circ} \mathrm{C}$ was promising in cosmetic and pharmaceutical industries and deserved to be investigated further more. In the article of Wang et $a l^{26}$, it took $3 \mathrm{~h}$ and $6 \mathrm{~h}$ when the cumulative release of ascorbic acid came to $50 \%$ at $37{ }^{\circ} \mathrm{C}$ for the microcapsule with $0.48 \mathrm{~g}$ ascorbic acid and $0.24 \mathrm{~g}$ ascorbic acid, respectively. For the microcapsule made in the paper, it took $3 \mathrm{~h}$ at $37^{\circ} \mathrm{C}$, the cumulative release of ascorbic acid came to $35 \%$, equaled to the encapsulation rate of microcapsules in $10 \mathrm{~d}$ at $25^{\circ} \mathrm{C}$ and in $22 \mathrm{~d}$ at $5{ }^{\circ} \mathrm{C}$. And it also took about $6 \mathrm{~h}$ and $15 \mathrm{~d}$ and $30 \mathrm{~d}$ came to the cumulative release of ascorbic acid at 37,25 and $5^{\circ} \mathrm{C}$.

\section{Conclusion}

This study suggests that tilapia scale might be successfully used in gelatin production, giving relatively high encapsulation 


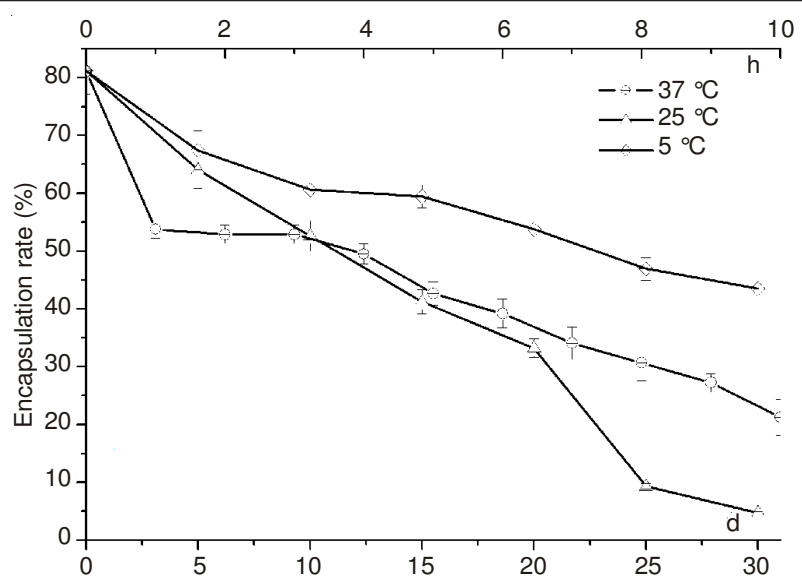

Fig. 5. Changes of encapsulation rate with time at different temperatures (Data are presented as mean $\pm \mathrm{SD}(\mathrm{n}=3)$ )

rate in microencapsulation technology. According to the experiment, the optimum preparation conditions were found to be $15 \mathrm{mg} / \mathrm{mL}$ FSG, $7.5 \mathrm{mg} / \mathrm{mL}$ ascorbic acid, $0.12 \mathrm{mg} / \mathrm{mL}$ TG, $150 \mu \mathrm{L}$ AEO- 9 and $40^{\circ} \mathrm{C}$ solidification temperature. This condition could obtain the microcapsules with encapsulation rate of $81.17 \%$ and average particle size of $5.73 \mu \mathrm{m}$. This promising property could create significant demand for tilapia gelatin which might then be used widely to replace commercial mammalian gelatin. Further study on the essence of the difference between the commercial gelatin and FSC in the application of microencapsulation technology will be carried out. The controlled-release properties of the microcapsule at 5, 25 and $37{ }^{\circ} \mathrm{C}$ might then be used widely in food, cosmetic and pharmaceutical industries.

\section{ACKNOWLEDGEMENTS}

This work was supported by Key Projects in the National Science \& Technology Pillar Program during the Twelfth Fiveyear Plan Period in China (2012BAD28B06-03).

\section{REFERENCES}

1. J. Thodesen (Da-Yong Ma), M. Rye, Y.-X. Wang, K.-S. Yang, H.B. Bentsen and T. Gjedrem, Aquaculture, 322-323, 51 (2011).

2. F. Zhang, S. Xu and Z. Wang, Food Bioprod. Process., 89, 185 (2011).

3. H. Yang and Y. Wang, Food Hydrocoll., 23, 577 (2009).

4. H.S. Tabarestani, Y. Maghsoudlou, A. Motamedzadegan and A.R. Sadeghi Mahoonak, Bioresour. Technol., 101, 6207 (2010).

5. M.H. Norziah, A. Al-Hassan, A.B. Khairulnizam, M.N. Mordi and M. Norita, Food Hydrocoll., 23, 1610 (2009).

6. S.S. Choi and J.M. Regenstein, J. Food Sci., 65, 194 (2000).

7. M.C. Gómez-Guillén, J. Turnay, M.D. Fernández-Díaz, N. Ulmo, M.A. Lizarbe and P. Montero, Food Hydrocoll., 16, 25 (2002).

8. A.A. Karim and R. Bhat, Food Hydrocoll., 23, 563 (2009).

9. T. Nagai, Food Chem., 68, 277 (2000).

10. S. Benjakul, K. Oungbho, W. Visessanguan, Y. Thiansilakul and S. Roytrakul, Food Chem., 116, 445 (2009).

11. N.F. Mohtar, C. Perera and S.-Y. Quek, Food Chem., 122, 307 (2010).

12. S. Wangtueai and A. Noomhorm, LWT-Food Sci. Technol., 42, 825 (2009).

13. K. Piez and J. Gross, J. Biol. Chem., 254, 995 (1960).

14. A.I. Sarabia, M.C. Gómez-Guillén and P. Montero, Food Chem., 70, $71(2000)$.

15. H. Umer, H. Nigam, A.M. Tamboli and M.S.M. Nainar, Int. J. Res. Pharm. Biomed. Sci., 2, 474 (2011).

16. W. Li, G. Wu, H. Chen and M. Wang, Colloids Surf. A, 333, 133 (2009).

17. K.L. Keller and N.A. Fenske, J. Am. Acad. Dermatol., 39, 611 (1998).

18. K. Makino, T. Mizorogi, S. Ando, T. Tsukamoto and H. Ohshima, Colloids Surf. B, 22, 251 (2001).

19. R.-N. Chen, H.-O. Ho and M.-T. Sheu, Biomaterials, 26, 4229 (2005).

20. E.Y. Backheet, K.M. Emara, H.F. Askal and G.A. Saleh, Analyst, 116, 861 (1991).

21. K. Yokoyama, N. Nio and Y. Kikuchi, Appl. Microbiol. Biotechnol., 64, 447 (2004).

22. G. Jing, T. Chen and M. Luan, Arabian J. Chem.; doi:10.1016/j.arabjc. 2011.06.007.

23. S. Sakai, S. Ito and K. Kawakami, Acta Biomater., 6, 3132 (2010).

24. P.M. Nielsen, Food Biotechnol., 9, 119 (1995).

25. T.-Y. Ting, I. Gonda and E. Gipps, Pharm. Res., 9, 1330 (1992).

26. H. Wang, H. Shi, A.C. Cheung and J.H. Xin, J. Control. Rel., 152(Suppl. 1), e78 (2011) 